\title{
Demographic, gadget and internet profiles as determinants of disease and consequence related COVID-19 anxiety among Filipino college students
}

\author{
Jerome V. Cleofas ${ }^{1}\left(\mathbb{0} \cdot \operatorname{lan}\right.$ Christopher N. Rocha ${ }^{2}(\mathbb{0}$
}

Received: 22 January 2021 / Accepted: 26 March 2021 / Published online: 4 April 2021

(c) The Author(s), under exclusive licence to Springer Science+Business Media, LLC, part of Springer Nature 2021

\begin{abstract}
In the context of the nationwide shift to online learning due to the COVID19 pandemic and its possible effect on mental health, this study investigated the relationship between demographic, gadget and Internet profiles, and disease and consequence related COVID-19 anxiety among Filipino college students. This is a quantitative cross-sectional study. A total of 952 students participated in the online survey. Descriptive and inferential statistics were used to draw insights from the data. Findings suggest that majority of the student respondents had high levels of disease and consequence related COVID-19 anxiety. Students from poorer households, who do not own laptops and desktop computers, and those with limited Internet connection exhibited higher levels of disease-related COVID-19 anxiety. Younger, poorer, female students who were enrolled in lower year levels, do not own laptops or tablets, and have limited or borrowed Internet connectivity demonstrated higher levels of consequencerelated COVID-19 anxiety.
\end{abstract}

Keywords College students · COVID-19 anxiety $\cdot$ Demographic profile $\cdot$ Gadget ownership $\cdot$ Internet connectivity

Jerome V. Cleofas

jerome.cleofas@dlsu.edu.ph

Ian Christopher N. Rocha

rocha1750018@ceu.edu.ph

1 Behavioral Sciences Department, College of Liberal Arts, De La Salle University, 2401 Taft Ave, Malate, 1004 Manila, Metro Manila, Philippines

2 School of Medicine, Centro Escolar University, 9 Mendiola St, San Miguel, 1005 Manila, Metro Manila, Philippines 


\section{Introduction}

Education is one of the sectors most badly hit by the coronavirus disease 2019 (COVID-19) pandemic. As of this writing, there are more than 119 million cases of COVID-19 all over the world (World Health Organization, 2021). Because of the need for social distancing to combat the spread of the virus, campuses in many countries have been closed. Many schools and universities have shifted to online learning mode. In the Philippines, this abrupt change in the educational landscape in the midst of the pandemic has been challenging. In October 2020, the country ranked 20th in the world in terms of the number of coronavirus cases and deaths (ABS-CBN News, 2020). This public emergency has placed a strain on students, teachers, administrators and other stakeholders (Tria, 2020).

An important student outcome monitored by COVID-19 studies is mental health. Many reports suggest the increase of psychological distress states among students such as anxiety, depression and suicidal ideation among many others during this outbreak (Cao et al., 2020; Islam et al., 2020; Lasheras et al., 2020; Olaimat et al., 2020; Rogowska et al., 2020; Tasnim et al., 2020). Consequently, the students experiencing stress have been found to have lower self-directed learning readiness during online classes (Heo \& Han, 2017). Aside from dealing with the challenging nature of the new face of academics, Filipino college students have to cope with the coronavirus public health emergency and its consequences in their social lives, while being in a country placed in the longest quarantine in the world (ABS-CBN News, 2020). This study specifically focuses on COVID-19 anxiety, which can be related to the fear of contracting the disease (disease-related COVID-19 anxiety) and fear of the negative effects of the disease in social life (consequence-related COVID-19 anxiety) as suggested by McElroy et al. (2020).

Disparities in mental health outcomes in a society are influenced by social inequality. Multiple studies link social background and anxiety among students (Lederer et al., 2020; Myhr et al., 2020; Shadmi et al., 2020). More specifically, COVID-19 related anxiety has been associated with demographic variables such as age (MoghanibashiMansourieh, 2020; Shevlin et al., 2020; Solomou \& Constantinidou, 2020; Tee et al., 2020), gender (Hou et al., 2020; McElroy et al., 2020; Tee et al., 2020), and economic status (Ettman et al., 2020; Poudel \& Subedi, 2020; Wang \& Tang, 2020).

Another form of social disadvantage that can increase anxiety is lack of access to digital resources such as computing gadgets and Internet connectivity (Poudel \& Subedi, 2020). Especially among students, the availability of these digital resources is vital for an effective participation in online college education and coping with many other challenges in the new normal (Kapasia et al., 2020). Increased gadget use during the pandemic has been suggested to improve social and cognitive health among students (Beng et al., 2020), while the lack of devices and connectivity for e-learning has been linked to increased stress among learners (Baticulon et al., 2021). Educational policies that design programs and provide human and financial resources to improve the information communication technology (ICT) integration in post-primary education have been emphasized (Alghamdi \& Holland, 2020), and are now indispensable necessities in this era of lockdown and remote learning. 
Clearly, COVID-19 magnifies the already inherent social and digital inequalities in society. In a developing country with one of the worst Internet connections in the South East Asian (ASEAN) region (Barreiro, 2017), the educational and mental health gaps between privileged and disadvantaged Filipino students are only expected to widen during this period of quarantine.

In the context of the educational shift due to the ongoing pandemic, and cognizant of the influences of social background and digital resources to student mental health, this study sought to determine the relationship between demographic, gadget and Internet profiles to disease and consequence related COVID-19 anxiety among Filipino college students.

\section{Methods}

\subsection{Research goal and design}

The present study measures COVID-19 anxiety among Filipino college students in terms of fear of contracting the disease (disease-related COVID-19 anxiety) and fear of the negative impacts of the disease to social life (consequence-related COVID-19 anxiety), and test their relationships with demographic, gadget and Internet profiles. This study uses a quantitative, cross-sectional, correlational design.

\subsection{Instrumentation}

There are three independent variables in the study: demographic characteristics, gadget ownership, and Internet connectivity. Demographic variables that were considered are as follows: (1) age, which was measured in years; (2) gender, which was measured as male [1] or female [0]; (3) year level, which included first to fifth year; (4) monthly family income, which was measured based on the National Economic Development Association brackets; and (5) type of institution, which was measured as private [1] or public [0]. In the Philippines, there are certain undergraduate degrees that have a five-year curriculum, such as in the fields of physical therapy and speech language pathology (Commission on Higher Education, 2015).

For gadget ownership, the participants were asked whether they owned one or more of the following electronic gadgets for regular and academic use: (1) smartphone; (2) laptop; (3) tablet; and (4) desktop computer. Also, the number of types of gadgets owned were measured in the study.

For Internet connectivity, two sub variables were included. First is the type of Internet connection they had at home. The answers were categorized into three: broadband or digital subscriber line (DSL), cellular service or mobile data, and connectivity that was borrowed from another household, or rented through a computer shop. The second sub variable is the duration of their connectivity on a daily basis, which was categorized as limited access (1-2 h only), moderate access (3-4 h only) and unlimited access. Please refer to Appendix Fig. 1 for the sample survey for demographic, gadget and Internet profiles. 
The dependent variable is COVID-19 anxiety. This was measured using the Pandemic Anxiety Scale (PAS) developed by McElroy et al. (2020). The PAS is a 5-point likert scale that measures two dimensions of COVID-19 anxiety. First is disease anxiety composed of four items (e.g. "I am worried that I will catch COVID19 "), with scores ranging from 4 to 20 . and Second is consequence anxiety with three items (e.g. "I'm worried about missing school/work"), with scores ranging from 3 to 15 . The scale has a satisfactory reliability score (Cronbach's alpha $=0.74$ ). We determined the individual levels of the summated scores as low, moderate and high through establishing cut-offs (Harpe, 2015) by dividing the range into three equal intervals and then rounding off. Information on the PAS can be accessed through McElroy et al. (2020).

\subsection{Sample and data collection}

The target population for this study are Filipino undergraduate students studying in higher education institutions in the Philippines, between the age 18 to 22, years old. This age range comprises the majority of undergraduate students in the country. We employed convenience sampling. The recruitment was done via our social media accounts through posting of the survey link. We asked our personal networks to also share it on their respective timelines and schools. Google forms was the platform used for to create the survey and collect the data. Postgraduate students were not included in the study. Ultimately, we were able to gather a total of 952 qualified student respondents for this study.

Our study complied with the ethical standards enshrined in the Helsinki Declaration. Full study details and informed consent were presented and secured respectively in the first page of the form. Privacy and confidentiality of the answers were maintained.

\subsection{Analysis of data}

To determine the profile of the respondents and the prevalence of the levels of COVID-19 anxiety, frequency, percentage, mean and standard deviation were used. To test the significant associations between the independent and dependent variables, Pearson R correlation and one-way ANOVA were used. Jamovi version 1.2 software for Mac was used for analysis.

\section{Results}

\subsection{Demographic profile of the respondents}

Table 1 shows that the majority of the participants are within the 18 to 19 -year-old age bracket $(\mathrm{f}=522 ; 54.8 \%)$, female $(\mathrm{f}=746 ; 78.4 \%)$, first year students $(\mathrm{f}=491$; $51.6 \%$ ), have an estimated monthly income of less than PHP 10,000 (USD 208) $(f=339 ; 35.6 \%)$, and are enrolled in a private university or college $(f=527 ; 55.4 \%)$. 
Table 1 Demographic profile of the respondents $(n=952)$

\begin{tabular}{|c|c|c|c|}
\hline Variable & Categories & $f$ & $\%$ \\
\hline \multirow[t]{2}{*}{ Age } & 18 to 19 years old & 522 & 54.8 \\
\hline & 20 to 22 years old & 430 & 45.2 \\
\hline \multirow[t]{2}{*}{ Gender } & Male & 206 & 21.6 \\
\hline & Female & 746 & 78.4 \\
\hline \multirow[t]{5}{*}{ Year Level } & 1st year & 491 & 51.6 \\
\hline & 2nd year & 333 & 35.0 \\
\hline & 3rd year & 44 & 4.6 \\
\hline & 4th year & 42 & 4.4 \\
\hline & 5 th year & 42 & 4.4 \\
\hline Estimated Monthly & More than PHP 200,000 & 27 & 2.8 \\
\hline \multirow[t]{6}{*}{ Family Income* } & PHP 125,001 to 200,000 & 22 & 2.3 \\
\hline & PHP 75,001 to 125,000 & 54 & 5.7 \\
\hline & PHP 40,001 to 75,000 & 93 & 9.8 \\
\hline & PHP 20,001 to 40,000 & 188 & 19.7 \\
\hline & PHP 10,001 to 20,000 & 229 & 24.1 \\
\hline & Less than PHP 10,000 & 339 & 35.6 \\
\hline \multirow[t]{2}{*}{ Type of Institution } & Public University/College & 425 & 44.6 \\
\hline & Private University/College & 527 & 55.4 \\
\hline
\end{tabular}

USD $1=$ PHP 48

\subsection{Gadget and internet profiles of the respondents}

Table 2 presents the gadget and Internet profiles of the respondents. In terms of gadgets, the majority of the respondents own a smartphone ( $\mathrm{f}=894 ; 93.9 \%)$ and own only one type of gadget ( $\mathrm{f}=476 ; 50.0 \%)$. In terms of Internet connectivity, the majority of the participants have their own subscription to a cellular or mobile service $(\mathrm{f}=498 ; 52.3 \%$ ) and have unlimited access $(\mathrm{f}=447 ; 47.0 \%)$.

\subsection{COVID-19 anxiety levels}

Table 3 presents the distribution of the respondents based on COVID-19 anxiety levels. Findings suggest that the majority of the respondents have high levels of disease-related $(\mathrm{f}=814 ; 85.5 \%)$ and consequence-related $(\mathrm{f}=737 ; 77.4 \%)$ COVID19 anxiety. The overall means and standard deviations for disease and consequence related anxiety are $17.28 \pm 3.25$ and $13.57 \pm 2.04$ respectively, both interpreted as high level.

\subsection{Relationship between demographic profile and COVID-19 anxiety}

Findings shown in Table 4 suggest that disease-related COVID-19 anxiety is significantly negatively correlated with monthly family income $(p<0.05)$. Students from 
Table 2 Gadget and internet profiles of the respondents $(n=952)$

\begin{tabular}{|c|c|c|c|}
\hline Variable & Categories & $f$ & $\%$ \\
\hline \multicolumn{4}{|l|}{ Gadget Profile } \\
\hline \multirow[t]{4}{*}{ Type of Gadget Owned } & Smartphone & 894 & 93.9 \\
\hline & Laptop & 469 & 49.3 \\
\hline & Tablet & 38 & 4.0 \\
\hline & Desktop Computer & 46 & 4.8 \\
\hline Number of Different & 4 different types of gadgets & 2 & 0.2 \\
\hline \multirow[t]{4}{*}{ Types of Gadgets Owned } & 3 different types of gadgets & 37 & 3.9 \\
\hline & 2 different types gadgets & 426 & 44.7 \\
\hline & 1 type of gadget only & 476 & 50.0 \\
\hline & No gadgets owned (borrowed only) & 11 & 1.2 \\
\hline \multicolumn{4}{|l|}{ Internet Profile } \\
\hline \multirow[t]{3}{*}{ Type Internet Connection } & Owned: Broadband or DSL & 431 & 45.3 \\
\hline & Owned: Cellular or Mobile Service & 498 & 52.3 \\
\hline & Not Owned: Rented/Borrowed & 23 & 2.4 \\
\hline \multirow[t]{3}{*}{ Daily Duration of Access } & Limited access (1-2 h only) & 209 & 22.0 \\
\hline & Moderate access (3-4 h only) & 296 & 31.0 \\
\hline & Unlimited access & 447 & 47.0 \\
\hline
\end{tabular}

families in lower income brackets are more anxious about the disease compared to their richer counterparts.

Furthermore, consequence-related COVID-19 anxiety was found to be significantly negatively correlated with age, gender, year level and family income $(p<0.05)$. Younger, female students from lower year levels and poorer families are more anxious about the consequences of the pandemic. Type of institution is not significantly related to the two domains.

Table 3 COVID-19 anxiety levels

\begin{tabular}{llll}
\hline Variable & Levels (Score Range) & $f$ & $\%$ \\
\hline Disease-Related & High (14-20) & 814 & 85.5 \\
COVID-19 Anxiety & Moderate (9-13) & 118 & 12.4 \\
& Low (4-8) & 20 & 2.1 \\
Consequence-Related & High (11-15) & 737 & 77.4 \\
COVID-19 Anxiety & Moderate (7-10) & 198 & 20.8 \\
& Low (3-6) & 17 & 1.8 \\
\hline
\end{tabular}


Table 4 Relationship between demographic profile (IV) and COVID-19 Anxiety (DV)

\begin{tabular}{llll}
\hline IV & DV & r-value & $p$ value \\
\hline Age & Disease-related & -0.010 & 0.759 \\
Gender & COVID-19 Anxiety & -0.039 & 0.224 \\
Year Level & & -0.042 & 0.195 \\
Monthly Family Income & & $-0.091^{*}$ & 0.005 \\
Type of Institution & & 0.023 & 0.469 \\
Age & Consequence-related & $-0.608^{*}$ & 0.036 \\
Gender & COVID-19 Anxiety & $-0.075^{*}$ & 0.021 \\
Year Level & & $-0.109 *$ & 0.001 \\
Monthly Family Income & & $-0.182^{*}$ & $<.001$ \\
Type of Institution & & 0.010 & 0.751 \\
\hline
\end{tabular}

*significant at $p=0.05$ level

\subsection{Relationship between gadget profile and COVID-19 anxiety}

Results shown in Table 5 suggest that disease-related COVID-19 anxiety is significantly negatively correlated with laptop and desktop ownership and the number of types of gadgets owned $(p<0.05)$. Higher disease anxiety scores are observed among those who do not own laptops or desktop computers, and have lesser types of gadgets owned.

On the other hand, consequence related COVID-19 anxiety was found to be significantly, negatively correlated with laptop and tablet ownership, and the number of gadget types owned $(\mathrm{p}<0.05)$. Those who do not own laptops and tablets, and have a lesser variety of gadgets exhibit higher levels of anxiety related to COVID-19 consequences. Smartphone ownership was not significantly related to the two domains of COVID-19 anxiety.

Table 5 Relationship between gadget profile (IV) and COVID19 Anxiety (DV)

\begin{tabular}{llll}
\hline IV & DV & r-value & p value \\
\hline Smartphone & Disease-related & 0.022 & 0.492 \\
Laptop & COVID-19 Anxiety & $-0.069 *$ & 0.034 \\
Tablet & & -0.051 & 0.114 \\
Desktop & & $-0.059^{*}$ & 0.030 \\
No. of Gadget Types & & $-0.079 *$ & 0.015 \\
Smartphone & Consequence-related & 0.022 & 0.499 \\
Laptop & COVID-19 Anxiety & $-0.125^{*}$ & $<.001$ \\
Tablet & & $-0.070^{*}$ & 0.032 \\
Desktop & & -0.059 & 0.068 \\
No. of Gadget Types & & $-0.138^{*}$ & $<.001$ \\
\hline
\end{tabular}

*significant at $p=0.05$ level 


\subsection{Relationship between internet profile and COVID-19 anxiety}

As seen in Table 6, ANOVA test results suggest significant differences in COVID19 anxiety based on Internet profile $(\mathrm{p}<0.05)$. Tukey's post hoc test was used to identify the specific groups with marked differences.

Broadband/DSL subscribers were seen to have significantly lower diseaserelated COVID-19 anxiety compared to those who only had cellular data subscriptions, and lower consequence-related COVID-19 anxiety compared to those subscribed to cellular service and those who rented/borrowed their Internet connectivity.

Respondents who had limited daily access to the Internet were seen to have significantly higher disease-related COVID-19 anxiety compared to those with unlimited access; and higher consequence-related COVID-19 anxiety compared to those with medium and unlimited access.

\section{Discussion}

The aim of this present study is to test the relationship between demographic, gadget and Internet profiles, and disease and consequence related COVID-19 anxiety among Filipino college students. As of this writing, this is the first large scale study done in the young adult, undergraduate student population in the country that looked into these determinants of COVID-19 anxiety. Our research suggests that high levels COVID-19 anxiety are prevalent among Filipino college students. Similarly, high rates of generalized and COVID-19-specific anxiety had been noted by previous studies in student populations in the Philippines (Baloran, 2020) and elsewhere (Cao et al., 2020; Islam et al., 2020; Lasheras et al., 2020; Olaimat et al., 2020; Rogowska et al., 2020) during the period of pandemic. The disruptive effects of the pandemic on the education, social life and future plans of these college students have truly negatively impacted their psycho-emotional status as emerging adults (Cleofas, 2020).

\subsection{Demographic, gadget and internet profiles, and disease-related COVID-19 anxiety}

Our present research demonstrates that students from poorer households have significantly higher disease-related COVID-19 anxiety. This correlation reflects the worry of those from the lower income bracket about having higher risks of getting infected. As the essential workers during quarantine are usually the poor, they are more exposed to the virus and may transmit it to other members of the household. Students with parents who are working outside the home during the pandemic, compared to those who are in a work-from-home scheme, have perceived increased susceptibility to the disease (Cleofas, 2020). Furthermore, the poor are less likely to afford testing and hospitalization related to COVID-19 (Shadmi et al., 2020). 


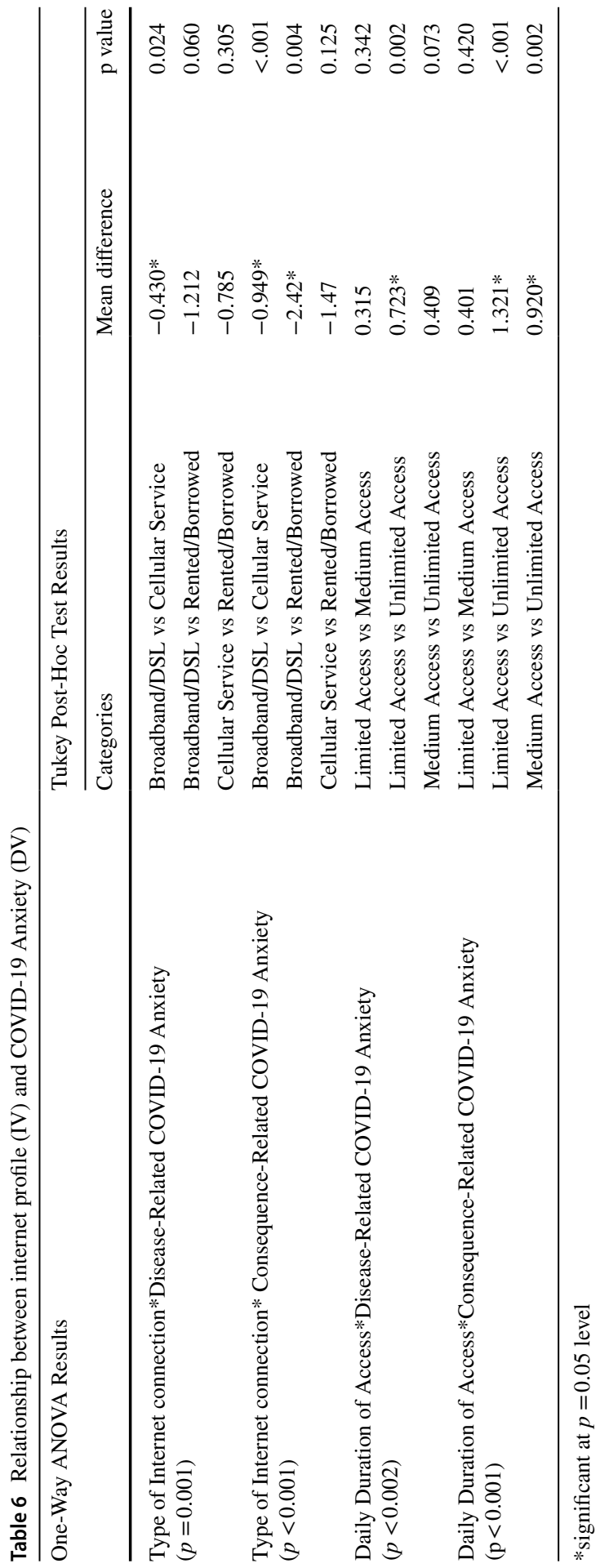


In terms of gadget profile, findings suggest that students who do not own laptops and desktop computers, and have a lesser variety of gadgets owned experience significantly higher disease-related COVID-19 anxiety. This association is expected since in the time of quarantine, the main source of information about the disease can be accessed via electronic gadgets (Ansari \& Anjali, 2020). Moreover, a study has suggested that compared to mobile devices, laptop and desktop searches provide better information regarding health (Boyd \& Wilson, 2018).

As for Internet profile, our present study shows that type of Internet connection and daily duration of Internet access are significant determinants of diseaserelated COVID-19 anxiety. Students whose main Internet connection is cellular service have higher levels of disease-related anxiety compared to those subscribed to broadband/DSL. Also, those with limited duration of Internet access have significantly higher levels of anxiety related to COVID-19 disease compared to those with unlimited access. Because of some limitations of cellular data plans to allow users access to certain social networking sites, the students may have more exposure to misinformation and non-contextualized news headlines that are found about COVID-19 in free sites, and may not have the means to verify. This exposure to false information may be the cause for increased anxiety towards COVID-19 as suggested by previous studies (Lee et al., 2020; Shabahang et al., 2020).

\subsection{Demographic, gadget and internet profiles, and consequence-related COVID-19 anxiety}

Our present study suggests that younger students and those enrolled in lower year levels exhibit higher levels of consequence-related COVID-19 anxiety compared to older counterparts. This finding is congruent with the study of Wang et al. (2020) that suggested that freshmen and sophomores scored higher in terms of anxiety, which reflects the uncertainties younger students have in terms of coping with the online pedagogy, while also transitioning into college life, both of which are affected because of the pandemic (Tria, 2020).

As regards to gender, females were found to have higher scores of consequence-related COVID-19 anxiety compared to their male counterparts. This finding is reflective of how quarantine and online schooling due to the pandemic can increase the home making and caretaking responsibilities of women in the household (Wenham et al., 2020), which causes the strain and anxiety among females as seen in other COVID-19 studies as well (McElroy et al., 2020; Wang et al., 2020; Tee et al., 2020).

Moreover, our research suggests that students from poorer households demonstrate higher levels of consequence-related COVID-19 anxiety, which confirms that people of lower socioeconomic status experience the social and economic impacts of the pandemic disproportionately (Shadmi et al., 2020). Anxieties 
among poor students have been related to the economic consequences of the pandemic such as financial distress because of parents losing employment, lack of basic needs and the need of the student to work to gain more income (Baticulon et al., 2021).

In terms of gadget profile, our findings show that those who do not own laptops and tablets, and those with a lesser variety of gadgets owned are significantly more anxious about the consequences of COVID-19. Owning computing devices with required specifications are important to successfully engage in distance learning as a consequence of the pandemic, and not owning gadgets that can properly run learning management systems is considered a barrier for online education (Baticulon et al., 2021; Cedeño et al., 2021), which can be a factor contributing to students' anxiety (Baloran, 2020; Pastor, 2020).

As for Internet profile, results suggest that students whose main Internet connection is cellular service, and those who borrow Internet from other households, have higher levels of consequence-related COVID-19 anxiety compared to those subscribed to broadband/DSL. Moreover, students who have less than five hours of daily Internet access are more anxious in terms of the consequences of COVID-19. Since online learning is highly dependent on Internet connection, which the Philippines still lacks in terms of national coverage (Barreiro, 2017), students with limited or unreliable connectivity will not be able to fully engage in class, which can be the source of anxiety for them (Baticulon et al., 2021; Pastor, 2020).

The findings on the negative relationships of family income, gadget ownership and quality of Internet connectivity with COVID-19 anxiety run parallel with each other. In order to effectively engage in online classes, obtain information on COVID19 and access essential digital services, students must own computing devices connected to reliable Internet connection (Baloran, 2020; Pastor, 2020). These are digital resources needed in order to participate in education and other facets of life in the new normal that require finances, which students from poorer households may lack (Baticulon et al., 2021). These explain the high level of anxiety observed in both economically and digitally challenged sectors of the undergraduate student population.

\section{Conclusions and recommendations}

Based on the findings, we conclude that demographic characteristics, gadget ownership and Internet access of college students are significant determinants of COVID19 anxiety. This study provides empirical evidence to support that socioeconomic gaps and the digital divide run parallel to each other and may lead to poor educational and mental health outcomes among students, especially in a time of pandemic.

Educational and psychological support for students during this online-mode period of education must focus on those who may experience higher levels of anxiety during the pandemic: the young, the females, the freshmen and the poor. School administrators must design less stressful digitized curricula and school experiences, conduct COVID-19 awareness campaigns, and implement 
counseling and mental health programs to care for students at risk for anxiety because of the pandemic.

Since gadget ownership is a protective factor for COVID-19 anxiety, government and civil society organizations may create programs to pool resources to provide computing devices to students from lower income brackets in order for them to successfully engage in online schooling and access to other digital services. Likewise, connection to a reliable Internet service is also a protective factor for COVID-19 anxiety. Local government units may provide financial support to students from poor households to be able to subscribe to stronger Internet connections. Internet service providers are enjoined to expand their coverage and introduce cheaper plans for students to help decrease the students' worries about being able to participate meaningfully in school.

The Philippines can learn from the strategies employed by the education sector of its ASEAN neighbors. For instance, students and teachers were provided financial support to obtain computing devices and dongles for internet connectivity in Singapore (Yip et al., 2021), and use of broadcast media and low-bandwidth communication apps were promoted in Thailand and Vietnam (Chang \& Yano, 2020). Through their Ministries of Education, the governments of Brunei Darussalam and Indonesia have forged partnerships with telecommunication companies to provide consistent Internet connectivity, free access to online learning management systems and platforms, and subsidized rates for students and teachers (Gupta \& Khairina, 2020; Shahrill et al., 2021). In Malaysia, the government provided RM270 (65 USD) to students studying in higher education institutions, and certain universities have placed support systems in order to provide technical assistance to students who have difficulty accessing reliable Internet services (Sia \& Adamu, 2020). In Lao PDR, the Ministry of Education and Sports have worked with civil society organizations in order to create applications for learning, equip schools with low-cost ICT equipment and provide trainings to teachers (Redmond, 2021).

\section{Limitations}

Despite a large sample size, it must be noted that the respondents were selected via convenience sampling and were limited to our social networks. Moreover, the current sample is predominantly female. Also, since the survey was administered online, the sample may not fairly represent students who completely do not have access to the Internet at all. These factors may affect the generalizability of the results. Also, due to the provisions of the Data Privacy Act of the Philippines (Official Gazette of the Philippines, 2012), we were not able to collect data on the institutions and locations of the students that voluntarily participated in the study, as these are considered personal and private information. Thus, we were not able to provide insight on the number of schools and regions that were included in this study. Future researchers may consider doing a similar study that will recruit a sample that aptly represents students in terms of gender, and also include those with entirely no Internet connectivity. 


\section{Appendix}

\section{SURVEY FORM}

1. Sociodemographic Profile

- Age (in years):

- Gender:

$$
\begin{array}{ll}
\circ & \text { Male } \\
\circ & \text { Female }
\end{array}
$$

- Year Level:

$$
\begin{array}{cl}
\circ & \text { First Year } \\
\circ & \text { Second Year } \\
\circ & \text { Third Year } \\
\circ & \text { Fourth Year } \\
\circ & \text { Fifth Year }
\end{array}
$$

- Type of Higher Education Institution:
- Public University/ College
- Private University/ College

- Living Arrangement:
- Living with Family
o Living with Friends/ Dormmates
- Living Alone

- Estimated Monthly Family Income:
- Less than PHP 10,000
o PHP 10,001 to 20,000
- PHP 20,201 to 40,000
PHP 40,001 to 75,000
PHP 75,001 to 125,000
- PHP 125,001 to 200,000
o More than PHP 200,000

\section{Gadget Profile}

- Gadgets used by Students during Online Class:
- Smartphone
- Laptop
- Tablet
- Desktop
- No gadget

3. Internet Profile

- Internet Access:

- Cellular service (mobile data)

- DSL through a phone company

- Broadband through a cable company

- Dial-up (must connect via phone dial)

- Rented

- Borrowed

- Time of Internet Access
- Limited access (1-2 hours)
- Medium access (3-4 hours)
- Unlimited access

\section{COVID-19 Anxiety}

- measured using the Pandemic Anxiety Scale [PAS] by McElroy et al., (2020)

Fig. 1 Sample survey of the study

\section{Declarations}

Conflict of interest There are no conflicts of interest to disclose.

\section{References}

ABS-CBN News. (2020). Topic page on philippines-coronavirus: ABS-CBN News. ABS-CBN News. https://news.abs-cbn.com/list/tag/philippines-coronavirus. Accessed 18 Dec 2020.

Alghamdi, J., \& Holland, C. (2020). A comparative analysis of policies, strategies and programmes for information and communication technology integration in education in the Kingdom of Saudi Arabia and the republic of Ireland. Education and Information Technologies, 25(6), 4721-4745. https:// doi.org/10.1007/s10639-020-10169-5.

Ansari, K. M. T., \& Anjali, A. K. (2020). Use of gadgets during COVID-19: A review. PalArch's Journal of Archaeology of Egypt/Egyptology, 17(7), 3319-3327. 
Baloran, E. T. (2020). Knowledge, attitudes, anxiety, and coping strategies of students during COVID19 pandemic. Journal of Loss and Trauma, 25(8), 635-642. https://doi.org/10.1080/15325024.2020. 1769300.

Barreiro, V. (2017). How fast are Internet speeds in ASEAN countries? Rappler. https://www.rappler. com/technology/Internet-speeds-asean-countries. Accessed 18 Dec 2020.

Baticulon, R. E., Sy, J. J., Alberto, N. R. I., Baron, M. B. C., Mabulay, R. E. C., Rizada, L. G. T., Tiu, C. J. S., Clarion, C. A. and Reyes, J. C. B. (2021). Barriers to online learning in the time of COVID-19: A national survey of medical students in the Philippines. Medical science educator. 1-12. https:// doi.org/10.1007/s40670-021-01231-z.

Beng, J. T., Tiatri, S., Lusiana, F., \& Wangi, V. H. (2020). Intensity of gadgets usage for achieving prime social and cognitive health of adolescents during the COVID-19 pandemic. In The 2nd Tarumanagara International Conference on the Applications of Social Sciences and Humanities (TICASH 2020), 735-741, Atlantis Press. https://doi.org/10.2991/assehr.k.201209.116.

Boyd, M., \& Wilson, N. (2018). Just ask Siri? A pilot study comparing smartphone digital assistants and laptop Google searches for smoking cessation advice. PLoS One, 13(3), E0194811. https://doi.org/ 10.1371/journal.pone.0194811.

Cao, W., Fang, Z., Hou, G., Han, M., Xu, X., Dong, J., \& Zheng, J. (2020). The psychological impact of the COVID-19 epidemic on college students in China. Psychiatry Research, 112934. https://doi.org/ 10.1016/j.psychres.2020.112934.

Cedeño, T. D. D., Rocha, I. C. N., Ramos, K. G., \& Uy, N. M. C. (2021). Learning strategies and innovations among medical students in the Philippines during the COVID-19 pandemic. International Journal of Medical Students, 9(1). https://doi.org/10.5195/ijms.2021.908.

Chang, G.C., \& Yano, S., 2020. How are countries addressing the Covid-19 challenges in education? A snapshot of policy measures. UKFIET: The Education and Development Forum. https://www.ukfiet. org/2020/how-are-countries-addressing-the-covid-19-challenges-in-education-a-snapshot-of-policymeasures/ (Accessed 16 March 2021).

Cleofas, J. V. (2020). Life interruptions, learnings and hopes among Filipino college students during COVID-19 pandemic. Journal of Loss and Trauma, 1-9. https://doi.org/10.1080/15325024.2020. 1846443.

Commission on Higher Education. (2015). Sample or Suggested Curricula for Undergraduate Programs in Different Disciplines Aligned to Outcomes-based Education. Commission on Higher Education.

Ettman, C. K., Abdalla, S. M., Cohen, G. H., Sampson, L., Vivier, P. M., \& Galea, S. (2020). Low assets and financial stressors associated with higher depression during COVID-19 in a nationally representative sample of US adults. Journal of Epidemiology and Community Health. https://doi.org/10. 1136/jech-2020-215213.

Gupta, D. \& Khairina, N. N. (2020). COVID-19 and learning inequities in Indonesia: Four ways to bridge the gap. World Bank Blogs. https://blogs.worldbank.org/eastasiapacific/covid-19-and-learning-inequ ities-indonesia-four-ways-bridge-gap. Accessed 23 March 2021.

Harpe, S. E. (2015). How to analyze Likert and other rating scale data. Currents in Pharmacy Teaching and Learning, 7(6), 836-850. https://doi.org/10.1016/j.cptl.2015.08.001.

Heo, J., \& Han, S. (2017). Effects of motivation, academic stress and age in predicting self-directed learning readiness (SDLR): Focused on online college students. Education and Information Technologies, 23(1), 61-71. https://doi.org/10.1007/s10639-017-9585-2.

Hou, F., Bi, F., Jiao, R., Luo, D., \& Song, K. (2020). Gender differences of depression and anxiety among social media users during the COVID-19 outbreak in China: A cross-sectional study. BMC Public Health, 20(1648). https://doi.org/10.1186/s12889-020-09738-7.

Islam, M. A., Barna, S. D., Raihan, H., Khan, M. N. A., \& Hossain, M. T. (2020). Depression and anxiety among university students during the COVID-19 pandemic in Bangladesh: A web-based crosssectional survey. PLoS One, 15(8), e0238162. https://doi.org/10.1371/journal.pone.0238162.

Kapasia, N., Paul, P., Roy, A., Saha, J., Zaveri, A., Mallick, R., Barman, B., Das, P., \& Chouhan, P. (2020). Impact of lockdown on learning status of undergraduate and postgraduate students during COVID-19 pandemic in West Bengal, India. Children and Youth Services Review, 116, 105194. https://doi.org/10.1016/j.childyouth.2020.105194.

Lasheras, I., Gracia-García, P., Lipnicki, D. M., Bueno-Notivol, J., López-Antón, R., de la Cámara, C., Lobo, A., \& Santabárbara, J. (2020). Prevalence of anxiety in medical students during the COVID19 pandemic: A rapid systematic review with meta-analysis. International Journal of Environmental Research and Public Health, 17(18), 6603. https://doi.org/10.3390/ijerph17186603. 
Lederer, A. M., Hoban, M. T., Lipson, S. K., Zhou, S., \& Eisenberg, D. (2020). More than inconvenienced: The unique needs of US college students during the CoViD-19 pandemic. Health Education \& Behavior. $10.1177 \% 2$ F1090198120969372.

Lee, J. J., Kang, K. A., Wang, M. P., Zhao, S. Z., Wong, J. Y. H., O’Connor, S., Yang, S. C., \& Shin, S. (2020). Associations between COVID-19 misinformation exposure and belief with COVID-19 knowledge and preventive behaviors: Cross-sectional online study. Journal of Medical Internet Research, 22(11), e22205. https://doi.org/10.2196/22205.

McElroy, E., Patalay, P., Moltrecht, B., Shevlin, M., Shum, A., Creswell, C., \& Waite, P. (2020). Demographic and health factors associated with pandemic anxiety in the context of COVID-19. British Journal of Health Psychology, 25(4), 934-944. https://doi.org/10.1111/bjhp.12470.

Moghanibashi-Mansourieh, A. (2020). Assessing the anxiety level of Iranian general population during COVID-19 outbreak. Asian Journal of Psychiatry, 51, 102076. https://doi.org/10.1016/j.ajp.2020. 102076.

Myhr, A., Anthun, K. S., Lillefjell, M., \& Sund, E. R. (2020). Trends in socioeconomic inequalities in Norwegian adolescents' mental health from 2014 to 2018: A repeated cross-sectional study. Frontiers in Psychology, 11, 1472. https://doi.org/10.3389/fpsyg.2020.01472.

Official Gazette of the Philippines. (2012). Republic Act No. 10173. https://www.officialgazette.gov.ph/ 2012/08/15/republic-act-no-10173/. Accessed 23 March 2021.

Olaimat, A. N., Aolymat, I., Elsahoryi, N., Shahbaz, H. M., \& Holley, R. A. (2020). Attitudes, anxiety, and behavioral practices regarding COVID-19 among university students in Jordan: A cross-sectional study. The American Journal of Tropical Medicine and Hygiene, 103(3), 1177-1183. https:// doi.org/10.4269/ajtmh.20-0418.

Pastor, C. K. L. (2020). Sentiment analysis on synchronous online delivery of instruction due to extreme community quarantine in the Philippines caused by COVID-19 pandemic. Asian Journal of Multidisciplinary Studies, 3(1), 1-6.

Poudel, K., \& Subedi, P. (2020). Impact of COVID-19 pandemic on socioeconomic and mental health aspects in Nepal. The International Journal of Social Psychiatry, 66(8), 748-755. https://doi.org/10. $1177 / 0020764020942247$.

Redmond, C. (2021). In Laos, children kept from learning by among world's most expensive internet. Globe Media Asia. https://southeastasiaglobe.com/laos-internet-access/. Accessed 23 March 2021.

Rogowska, A. M., Kuśnierz, C., \& Bokszczanin, A. (2020). Examining anxiety, life satisfaction, general health, stress and coping styles during COVID-19 pandemic in polish sample of university students. Psychology Research and Behavior Management, 13, 797. https://doi.org/10.2147/PRBM.S266511.

Shabahang, R., Aruguete, M. S., \& McCutcheon, L. E. (2020). Online health information utilization and online news exposure as predictor of COVID-19 anxiety. North American Journal of Psychology, 22(3), 469-482.

Shadmi, E., Chen, Y., Dourado, I., Faran-Perach, I., Furler, J., Hangoma, P., Hanvoravongchai, P., Obando, C., Petrosyan, V., Rao, K. D., Ruano, A. L., Shi, L., de Souza, L. E., Spitzer-Shohat, S., Sturgiss, E., Suphanchaimat, R., Uribe, M. V., \& Willems, S. (2020). Health equity and COVID-19: Global perspectives. International Journal for Equity in Health, 19(104). https://doi.org/10.1186/ s12939-020-01218-z.

Shahrill, M., Petra, M. I., Naing, L., Yacob, J., Santos, J. H., \& Aziz, A. B. A. (2021). New norms and opportunities from the COVID-19 pandemic crisis in a higher education setting: Perspectives from Universiti Brunei Darussalam. International Journal of Educational Management. https://doi.org/ 10.1108/IJEM-07-2020-0347.

Shevlin, M., McBride, O., Murphy, J., Miller, J. G., Hartman, T. K., Levita, L., Mason, L., Martinez, A. P., McKay, R., Stocks, T., Bennett, K. M., Hyland, P., Karatzias, T., \& Bentall, R. P. (2020). Anxiety, depression, traumatic stress and COVID-19-related anxiety in the UK general population during the COVID-19 pandemic. BJPsych Open, 6(6), e125. https://doi.org/10.1192/bjo.2020.109.

Sia, J. K. M., \& Adamu, A. A. (2020). Facing the unknown: Pandemic and higher education in Malaysia. Asian Education and Development Studies, 10(2). https://doi.org/10.1108/AEDS-05-2020-0114.

Solomou, I., \& Constantinidou, F. (2020). Prevalence and predictors of anxiety and depression symptoms during the COVID-19 pandemic and compliance with precautionary measures: Age and sex matter. International Journal of Environmental Research and Public Health, 17(14), 4924. https://doi.org/ 10.3390/ijerph17144924.

Tasnim, R., Islam, M. S., Sujan, M. S. H., Sikder, M. T., \& Potenza, M. N. (2020). Suicidal ideation among Bangladeshi university students early during the COVID-19 pandemic: Prevalence estimates 
and correlates. Children and Youth Services Review, 119, 105703. https://doi.org/10.1016/j.child youth.2020.105703.

Tee, M. L., Tee, C. A., Anlacan, J. P., Aligam, K., Reyes, P., Kuruchittham, V., \& Ho, R. C. (2020). Psychological impact of COVID-19 pandemic in the Philippines. Journal of Affective Disorders, 277 , 379-391. https://doi.org/10.1016/j.jad.2020.08.043.

Tria, J. Z. (2020). The COVID-19 pandemic through the lens of education in the Philippines: The new normal. International Journal of Pedagogical Development and Lifelong Learning, 1(1), ep2001. https://doi.org/10.30935/ijpd1l/8311.

Wang, G. Y., \& Tang, S. F. (2020). Perceived psychosocial health and its sociodemographic correlates in times of the COVID-19 pandemic: A community-based online study in China. Infectious Diseases of Poverty, 9(1), 148. https://doi.org/10.1186/s40249-020-00770-8.

Wang, C., Zhao, H., \& Zhang, H. (2020). Chinese college students have higher anxiety in new semester of online learning during COVID-19: A machine learning approach. Frontiers in Psychology, 11, 3465. https://doi.org/10.3389/fpsyg.2020.587413.

Wenham, C., Smith, J., \& Morgan, R. (2020). COVID-19: The gendered impacts of the outbreak. The Lancet, 395(10227), 846-848. https://doi.org/10.1016/S0140-6736(20)30526-2.

World Health Organization. (2021). WHO coronavirus disease (COVID-19) dashboard. World Health Organization. https://covid19.who.int. Accessed 16 March 2021.

Yip, W., Ge, L., Ho, A. H. Y., Heng, B. H., \& Tan, W. S. (2021). Building community resilience beyond COVID-19: The Singapore way. The Lancet Regional Health-Western Pacific, 7. https://doi.org/10. 1016/j.lanwpc.2020.100091.

Publisher's note Springer Nature remains neutral with regard to jurisdictional claims in published maps and institutional affiliations. 